\title{
GESTÃO DA COMUNICAÇÃO NO DESENVOLVIMENTO REGIONAL
}

\section{Só a gestão da comunicação para a efetiva participação das comunidades poderá melhorar os resultados de projetos governamentais de desenvolvimento}

A globalização é um fenômeno que, considerado quer no aspecto econômico, quer no aspecto cultural, apresenta uma interface aparentemente paradoxal. É universal mas é excludente, é global mas se materializa no local, engendrando novas formas de sociabilidade. O local se constitui como o espaço privilegiado onde se desenvolvem relações combinatórias das culturas locais, de assimilação, rejeição e refuncionalização da cultura global hegemônica, constituindo aquilo que o sociólogo inglês Roland Robertson' chama de glocalização, uma mistura de globalização com características locais.

A glocalização, portanto, engendra não apenas novas formas de sociabilidade, como suscita a necessidade de novas formas de lutas, capazes de enfrentar um dos efeitos de que a globalização parece ser indutora: a exclusão social.

A preocupação com os efeitos excludentes da globalização já é algo visível no mundo. A prova disso é o fato de a ONU ter escolhido para a $9^{\mathrm{a}}$ Conferência das Nações Unidas sobre o Comércio e o Desenvolvimento, realizada este ano na África do Sul, o tema/questão: Como evitar que uma economia cada vez mais globalizada aumente o número de excluídos e marginalizados?

A resposta a essa questão se materializa através das iniciativas governamentais no sentido de encontrar novas formas de empreendimentos dentro de uma dinâmica de desenvolvimento territorializada. Nesse processo, a construção das velhas identidades nacionais cede lugar à organização popular na comunidade, no município, tendo a participação dos munícipes na construção da nova cidadania, entendida como a via para o desenvolvimento local.

Uma dessas iniciativas de desenvolvimento local está sendo executada pelo governo, no Nordeste do Brasil. A análise dessa experiência na perspectiva da gestão comunitária da comunicação é o objetivo deste artigo.

\section{DESENVOLVIMENTO \\ LOCAL E PARTICIPAÇÃO}

A preocupação com o desenvolvimento local na direção em que entendemos hoje - como um esforço de mobilização de grupos na comunidade, no município a fim de desenvolver, em parceria com o Estado e Oganizações Não-Governamentais (ONG),

\section{A AUTORA}

\section{Maria Salett Tauk Santos}

Doutora em Ciências da Comunicação pela ECA-USP e professora da Universidade Federal Rural de Pernambuco.

1. A expressão foi utilizada pelo Professor Roland Robertson, da Universidade de Pittsburg (EUA), em Conferência durante o Seminário Pluralismo Cultural, Identidade e Globalização, no Rio de Janeiro. Cf. FOLHA DE S. PAULO. Ilustrada, 12 de abril de 1996. p.6. 
ações empreendedoras ligadas à sobrevivência ${ }^{2}$ - tem sua origem no final dos anos 80. A crise do emprego e do Estado providência e suas repercussões sobre as comunidades locais, as regiões e os movimentos sociais estão, como assinala Louis Favreau ${ }^{3}$, na base dessa questão.

Favreau, tomando como referência países como Canadá, França e Estados Unidos, analisa a situação dos principais atores do desenvolvimento local como o Estado, as empresas privadas, os movimentos sociais e as comunidades locais, demonstrando como, dentro da ordem da globalização, esses atores são impelidos a um rearranjo em nível local para lutar contra a exclusão e alcançar o desenvolvimento. O Estado, por se encontrar sujeito às regras da reestruturação mundial da economia e da crise das despesas públicas, procura como saída intervir de forma mais localizada em parceria com os diferentes setores da sociedade. As grandes empresas, à medida que se adequam à ordem econômica vigente, provocam uma redução drástica no nível de emprego, tornando-se fomentadoras de exclusão. Para escapar a esse estigma, essas empresas procuram, em parceria com o setor público e as comunidades, alternativas locais para o problema $^{4}$. Os movimentos sociais redefinem suas estratégias de intervenção, antes limitadas apenas à esfera reinvindicatória, no domínio do econômico, estabelecendo, como assinala Levesque e Mager, parcerias com os setores público e privado5. Por sua vez, as comunidades locais, sentindo-se ameaçadas na sua coesão social pelo aumento da pobreza, e expostas à violência de todas as ordens, tendem a trabalhar em concertação com os demais atores locais, participando de programas de desenvolvimento econômico e social.

A construção do desenvolvimento local passa, portanto, por uma nova cultura política.

Construir uma nova cultura política pressupõe, como assinala Marilena Chauí, estimular formas de auto-organização da sociedade e sobretudo das camadas populares, criando o sentimento $\mathrm{e}$ a prática da cidadania participativa ${ }^{6}$.

Essa compreensão já é antiga no âmbito dos movimentos sociais no Brasil. O exemplo mais recente é o esforço desenvolvido pela Ação da Cidadania contra a Fome, a Miséria e pela $\mathrm{Vida}^{7}$ que, na luta pela democratização do processo de formulação e implementação das políticas sociais, elegeu o Estado como parceiro dessa luta. O novo é o Estado, que historicamente exerceu um papel centralizador, tomando a iniciativa de privilegiar a participação das comunidades locais na tomada de decisões e estabelecendo parcerias com ONGs na construção do desenvolvimento local. Esse dado é inovador sobretudo quando se trata de planejar o desenvolvimento rural no Brasil, particularmente na região Nordeste.

2. A esse respeito ver: SANTOS, Maria Salett Tauk; CALLOU, Angelo Brás Fernandes. Desafios da comumicação rural em tempo de desenvolvimento local. SIGNO - Revista de Comunicação Integrada. João Pessoa: UFPB, Ano II, n.3, set. de 1995. p.42-47.

3. FAVREAU, Louis. Quartiers en crise: revitalisation et développement local en milieu urbain. (O bairro em crise: revitalização e desenvolvimento local no meio urbano) Coopératives et développment. Revie du Ciriec. Canadá, v.26, n.2, 19941995. p.7.

4. Idem. ibid. p.7-8

5. LEVESQUE, B., MALO, M.C, apud FAVREAU, Louis, op, cit, p.8.

6. CHAUf, Marilena. Cultura política e política cultural. Estudos Avançados. São Paulo: IEA-USP, n.23, 1995. p.71.

7. Movimento liderado pelo sociólogo brasileiro Herbert de Souza, falecido em 1997, com o objetivo de mobilizar a sociedade civil e o Estado contra a fome. 


\section{POLÍTICA DE ESTADO E GESTÃO COMUNITÁRIA}

O Programa Reformulado de Apoio ao Pequeno Produtor Rural (PAC/FUMAC) nasce dessa proposta de redefinição das políticas públicas do Estado para o meio rural nordestino, expressa no objetivo de "estimular através de financiamentos e de investimentos, empreendimentos selecionados e solicitados por comunidades rurais carentes organizadas"8. A identificação, o planejamento, a execução, fiscalização e controle desses projetos são competência inalienável das populações rurais organizadas, no afã de contribuir para o "fortalecimento do processo de organização e participação das comunidades" 9 e ao mesmo tempo contribuir para o "aperfeiçoamento do processo de tomada de decisões em nível municipal" com a "efetiva participação das comunidades" 10 .

Entre as diretrizes e critérios para a implantação do Programa estão ainda previstas ações de concertação entre as Unidades Técnicas executoras do PAC/FUMAC com as ONGs, para o esforço de mobilização comunitária, além da realização de campanhas publicitárias no sentido de divulgar o Programa e persuadir as comunidades rurais a participar.

A concepção do Programa PAC/FUMAC contempla todos os principais elementos para o desencadeamento de um processo de desenvolvimento local. Há um Estado que convoca os cidadãos a assumirem responsabilidades e dividir poder; existe um trabalho de promover a concertação dos diferentes atores sociais - empresas privadas, ONGs, comunidades -, no esforço para o desenvolvimento; há uma intenção de mobilizar as comunidades para o exercício da cidadania municipal. Entretanto, uma pesquisa avaliatória recente demonstra que não foi significativa a contribuição do Programa para o incremento da participação das comunidades nordestinas envolvidas"

Considerando a participação enquanto processo de comunicação, é possível proceder a uma análise dos fatores que explicam em parte esse insucesso. $\mathrm{O}$ procedimento dessa análise será o de comparar alguns fundamentos da teoria da participação às estratégias para a gestão comunitária do PAC/FUMAC e ao comportamento de participação das comunidades rurais envolvidas pelo Programa.

Desde a Declaração Universal dos Direitos Humanos que o pensamento social converge no sentido de considerar a participação popular como "um direito humano, um dever político e um instrumento essencial de construção nacional”. Pedro Demo coloca como objetivos da participação "a autopromoção, a realização da cidadania, a implementação de regras democráticas de jogo, o controle do poder, controle da burocracia, o estabelecimento da negociação e a construção de uma cultura democrática"'2. Cecília Peruzzo fala da participação popular nos domínios da produção, planejamento e gestão como "parte no processo de democratização e conquista dos direitos huma-

\footnotetext{
8. PROGRAMA DE APOIO AO PEQUENO PRODUTOR - PAPP. Diretrizes e critérios para a implantação do Programa Reformulado de Apoio ao Pequeno Produtor Rural (PAPP). Recife, 12 de março de 1993. p.2. (mimeo)

9. Idem. ibid.

10. Idem. ibid.

11. Sobre a pesquisa avaliatória do Programa PAC/FUMAC, ver: IICA/UFRPE/FUNDAJ/FADURPE. Relatório de avaliação do segmento organização/participação comunitária do programa PAC/FUMAC. (Pesquisadores responsáveis: Angelo Brás Fernandes Callou, Maria Salett Tauk Santos), Recife, março de 1996. (mimeo).
}

12. DEMO, Pedro. Participação é conquista. São Paulo: Cortez, 1988. p.67. 
nos, com a potencialidade de ajudar a formular novos valores culturais e políticos"13.

Ao estimularem projetos a serem identificados, planejados e executados pela comunidade "contribuindo para o fortalecimento do processo de organização e participação das referidas comunidades", o objetivo do PAC/FUMAC, aparentemente, era o de tornar essas comunidades gestoras desses projetos. Objetivo, portanto, coerente com a teoria da participação. Há que se considerar, entretanto, que, ao eleger como critério o de apenas trabalhar com as comunidades carentes organizadas, o Programa pressupõe que essas comunidades possuem a priori um nível de organização que as credencia a uma participação consensual, resultante de um complexo e lento processo de motivação e mobilização, no qual se combinam necessidades objetivas e subjetivas das pessoas envolvidas ${ }^{14}$. Quem conhece a situação de desinformação, atraso e isolamento em que vive imersa a população pobre do meio rural do Nordeste brasileiro, sabe que é raro esse nível de participação.

Historicamente submetida a um tratamento paternalista do Estado, que the negou o direito à participação na determinação das políticas públicas, o simples fato de convocar esta população a participar de uma associação e opinar sobre os projetos governamentais não garante o sucesso da experiência de autogestão.

Durante o processo avaliatório pôde-se observar que existe um bom nível de comunicação interpessoal entre os técnicos do PAC/FUMAC e os membros das associa- ções beneficiárias do Programa. Há uma certa cumplicidade nas relações pessoais profissionais dos técnicos com a população envolvida. Entretanto, não se pode afirmar que esse clima amistoso esteja provocando impacto significativo sobre a organização/participação comunitária. Isso se explica, por um lado, pelo fato de os técnicos serem oriundos de organizações governamentais que, no caso brasileiro, não possuem tradição de trabalho participativo em contextos populares; e por outro lado, porque o trabalho dos técnicos junto às comunidades se esgota quando o projeto é implantado. Ou seja, no momento em que a assessoria do técnico é indispensável à aprendizagem da autogestão, da autopromoção, da gestão comunitária, enfim.

A descontinuidade do processo da comunicação entre os técnicos do $\mathrm{PAC} / \mathrm{FU}$ MAC e as organizações comunitárias acaba por reforçar as antigas relações de paternalismo predominantes nos programas governamentais para as populações pobres do meio rural. Historicamente a sobrevivência das populações pobres do Nordeste brasileiro encontra-se condicionada, como assinala Horácio Martins, à capacidade de essas populações receberem benefícios governamentais ou favores dos setores hegemônicos da sociedade local ${ }^{15}$. Nesse sentido, a adesão das comunidades rurais às associações se dá muito mais em virtude das exigências associativas do governo, para que essa população tenha acesso aos benefícios públicos, do que como resultado de um processo participativo de gestão comunitária da população envolvida. A prova está nas entrevistas realizadas com membros das associa-

13. PERUZZO, Cecília M. Krohling. A participação na comunicação popular. São Paulo, ECA-USP, 1991. 179p. (Tese de Doutorado).

14. A esse respeito ver: CARVALHO, Horácio Martins de. Participação e cidadania. Projeto Áridas. Brasília, Secretaria de Planejamento, Orçamento e Coordenadoria da Presidência da República, 1994. (mimeo).

15. CARVALHO, Horácio Martins de. op. cit., p.13. 
ções comunitárias que, em muitos casos, não conhecem sequer o nome da associação à qual pertencem. Mais grave ainda é o caso de alguns presidentes de associações que revelaram desconhecer a própria função na organização, embora assinem documentos como tal.

Analfabetos ou semi-analfabetos, em sua maioria, se considerarmos que $51 \%$ da população entrevistada possui menos que o primeiro grau de escolaridade, e sem um acompanhamento sistemático à formação para a participação, a população envolvida no PAC/FUMAC fica à mercê de políticos, sobretudo na esfera municipal, que condicionam o acesso aos benefícios do Programa ao apoio eleitoral das comunidades e suas associações.

Acostumadas a essa relação de subalternidade quando se trata de obter algum benefício governamental, os contextos populares levam as suas associações a uma "participação subalterna", reduzindo a organização popular à condição de ter acesso a alguma ajuda do governo.

Nesse sentido, ao serem indagados sobre o motivo de participarem das associações, quase $50 \%$ dos entrevistados responderam "para obter benefícios", "para receber auxílio do governo" 16 .

Ao propor como estratégias para o desenvolvimento do Programa PAC/FUMAC ampla campanha publicitária através dos meios de comunicação de massa e os acordos com organizações públicas e não-governamentais, no sentido de mobilizar a população potencialmente beneficiária, o gover- no brasileiro pareceu apostar na noção de que bastariam informações básicas e instrumentais para que a participação se efetivasse. A participação, entretanto, é um caminho longo e lento. Pressupõe um amplo processo de comunicação que possibilite às pessoas envolvidas superarem condicionamentos culturais. A cultura constitui, portanto, o espaço chave a ser considerado quando o objetivo da comunicação é desenvolver formas de organização para a prática da gestão comunitária. Nessa perspectiva, quando se trata de construir o desenvolvimento local, é fundamental que a comunicação funcione como facilitadora das mediações ${ }^{17}$ da cultura hegemônica global, materializada nas propostas associativistas do Estado, da cultura local, da população pobre, do meio rural em seu subjetivismo e individualidade.

\section{CULTURAS LOCAIS}

É preciso estar atento às mediações das culturas locais em tempo de globalização. São elas que desenham os contornos da nova cidadania, a que emerge nos espaços da glocalização, das relações do geral (global) com o particular (local). Não se pode reverter a globalização, mas pode-se submetê-la às decisões das maiorias no âmbito das comunidades, dos municípios, das nações. Por outro lado, as ações de gestão comunitária limitadas ao âmbito local de um município não devem perder de vista a perspectiva do global, sem que essa perspectiva caracterize um processo de subordinação.

A visão do desenvolvimento local como espaço de mediações do global/local e

16. IICA/UFRPE/FUNDAJ/FADURPE. Relatório de avaliação do segmento... op.cit. p.28.

17. Simplificadamente, pode-se dizer que mediações são os filtros por que passam quaisquer tipos de comunicação. Exemplificando: entre o fato ocorrido e o fato relatado há a mediação (os filtros) de quem faz o relato, que o faz a partir de seu ponto de vista, de sua cultura, de seus interesses. O processo de produção de uma mensagem jornalística, ou não, é repleto de mediaçōes, pois desde o repórter, ou qualquer outra pessoa, até o receptor da mensagem, o qual também procede à seleção e à compreensão a partir de um conjunto de fatores que operam em sua vida em seu cotidiano, esses filtros estão atuando. (N.E.). 
do local como a esfera de produção de sentido e da ação, permite encontrar saídas para viabilizar a gestão comunitária, tornando mais ágil o enfrentamento dos problemas imediatos da fome, do desemprego, da saúde, da educação, da migração, da exclusão no Brasil. Permite, também, proporcionar as bases para o desenvolvimento de programas

Resumo: A autora analisa a experiência de um programa governamental de desenvolvimento de comunidades pobres do Nordeste do Brasil, tendo como perspectiva a gestão comunitária da comunicação no processo de luta contra a exclusão social. Toma o local como espaço privilegiado onde se materializam as mediaçōes culturais do global. Destaca a necessidade de participaçaáo efetiva da comunidade em açōes governamentais de promoção, condenando os processos nos quais o paternalismo politico prevaleça.

Palavras-chave: comunidade, gestāo da comunicação, organizaçăo popular, globalização, programa governamental a longo prazo, como os voltados para a Educação, pois se as novas tecnologias e os meios de comunicação, enquanto manifestações do global, podem ajudar a suprir uma lacuna extensa de dívida social com as populações menos privilegiadas, têm que atuar levando em consideração as demandas das comunidades, do local.

Abstract: The author analyzes the experience of a governmental program for the development of the poor communities in Northeastern Brazil, having as a perspective the community management of communication in the process of fighting against social exclusion. The author takes the location as a privileged space where the global cultural mediations are materialized and highlights the need for effective community participation in governmental actions for promotion, disapproving processes in which political paternalism prevails.

Keywords: community, communication management, popular organization, globalization, governmental program. 